\title{
Role of ultrasonography in diagnosis of solid space occupying lesion in the liver correlation with FNAC
}

\author{
Roy $\mathrm{SK}^{1}$, Sultana $\mathrm{S}^{2}$, Mollah $\mathrm{NU}^{3}$, Yasmin $\mathrm{T}^{4}$, Sarker $\mathrm{A}^{2}$, Jahan $\mathrm{MU}^{5}$ \\ ${ }^{I}$ Department of Radiology \& Imaging, Sir Salimullah Medical College \& Mitford Hospital, Dhaka, \\ ${ }^{2}$ Department of Radiology \& Imaging, BSMMU, Dhaka, ${ }^{3}$ Department of Oncology, BSMMU, \\ ${ }^{4}$ Department of Radiology \& Imaging, Enam Medical College \& Hospital, ${ }^{5}$ Consultant Radiologist \\ Email: shyamalradio2008@gmail.com
}

\begin{abstract}
This cross sectional study was carried enrolling 47 subjects with suspected solid liver mass, in the Department of Radiology and Imaging, Dhaka Medical College Hospital, Dhaka, over a period of twelve months. The aim of this study was to evaluate the diagnostic usefulness of transabdominal ultrasonography in the diagnosis of solid SOL in the liver. Majority of the respondents $(42.55 \%)$ were found between 41-60 years of age. Five (10.63\%) subjects were found below 20 years of age. There were 31 men $(65.95 \%)$ and 16 women $(34.05 \%)$. Majority of the metastasis were multiple (85\%), hypoechoic (35\%) and only $15 \%$ had internal calcifications. HCC was single lesion $(61.53 \%)$ with hyperechoic $(38.35 \%)$ echogenicity, with a central halo $(76.92 \%)$ and $15.38 \%$ had internal calcifications. Majority of the cholangiocarcinoma were solitary $(80 \%)$, hypoechoic $(60 \%)$ and $60 \%$ had internal calcifications. Hepatoblastoma were solitary and had calcifications $(60 \%)$ with mixed echogenicity $(60 \%)$. Majority of the adenomas were solitary $(80 \%)$, hypoechoic $(60 \%)$ and only 20 $\%$ had internal calcifications. The validity of transabdominal sonography for the diagnosis of metastasis was confirmed by calculating sensitivity (100\%), specificity (96.42\%), accuracy (97.87\%), positive (95\%) and negative predictive $(100 \%)$ values by using the standard formula given. The sensitivity, specificity, accuracy, positive and negative predictive values for HCC were $92.3 \%, 97.05 \%, 95.74 \%, 92.3 \%$ and $97.05 \%$ respectively. The sensitivity, specificity, accuracy, positive and negative predictive values for cholangiocarcinoma and hepatoblastoma were $80 \%$, $97.61 \%, 95.74 \%, 80 \%$ and $97.61 \%$ respectively. Sensitivity, specificity, accuracy, positive and negative predictive values were $80 \%, 100 \%, 97.87 \%, 100 \%$ and $97.67 \%$ respectively for adenoma. From the study result it was concluded that transabdominal ultrasonography could be reliable, nonionizing and relatively cheap procedure for diagnosis solid hepatic mass lesion.
\end{abstract}

\section{Introduction}

The liver is involved by many non-neoplastic and neoplastic diseases. Evaluation and management of hepatic lesions is a common clinical problem and their appropriate clinical management depends on accurate diagnosis. ${ }^{1}$ Ultrasonography, $\mathrm{CT}$ and magnetic resonance have been widely used in the diagnosis of liver diseases in the past 20 years, but the final definite diagnosis of space occupying (SOL) lesions of liver cannot be made only by imaging methods. Ultrasonography has been used in combination with fine-needle aspiration cytology in the diagnosis of liver diseases since the 1970s. It is not difficult to find out SOL with wide application of imaging methods, but it is still troublesome to make an accurate and definite diagnosis of tumors. Combined methods should be advocated for the diagnosis of SOL by USG-guided fine needle aspiration cytology in order to improve the accuracy of its diagnosis. FNAC is mainly used at present in the diagnosis of SOL by ultrasonography and CT. Fine-needle liver aspiration cytology is performed when the final definite diagnosis cannot be made. ${ }^{2}$

Ultrasonography is generally the first imaging modality of choice for the primary evaluation of focal liver lesions; however, the B-mode ultrasonographic features of solid lesions are often not clear-cut and generally overlap. Early detection and characterization of focal liver lesions will improve the success rate of surgical resection, 
percutaneous ablation therapy, or chemotherapy. ${ }^{3}$ Because appropriate clinical management is guided by the nature of the mass, accurate diagnosis of discrete hepatic masses is very important. Despite recent improvement, radiological imaging does not always allow precise diagnosis of the lesions. Therefore, a tissue diagnosis is often required to guide subsequent management. Fine needle aspiration cytology (FNAC) under image guidance has gained increasing acceptance as the diagnostic procedure of choice for patients with focal hepatic lesions. It can be performed percutaneously or endoscopically. There are several diagnostic procedures to obtain preoperative tissue diagnosis to guide subsequent therapy. They include image guided fine needle aspiration cytology, blind percutaneous needle core biopsy and trans jugular needle core biopsy. ${ }^{4}$ Blind liver cytology is now almost obsolete. The main indications for fine needle aspiration cytology (FNAC) of the liver were in the diagnosis of localized malignant deposits, including both primary hepatocellular neoplasm and metastatic tumors. Guiding the needle with diagnostic imaging techniques, particularly ultrasound or CT is usually recommended. ${ }^{5}$ Ultrasound guided needle cytology is an important diagnostic technique in radiology practices throughout the world. It has become an accurate, safe and widely accepted technique for diagnosis of hepatic lesion. It also decreases patient costs by obviating the need for an operation, decreasing the duration of hospital stay and decreasing the number of examination necessary during a diagnostic evaluation.

Traditionally, ultrasound-guided needle cytology has been used for the biopsy of large, superficial and cystic masses. Currently, however because improvements in instrumentation and cytology techniques - small, deeply located and solid masses can also undergo accurate cytology. ${ }^{6}$ Sonography depicts abnormal findings in a number of disease states, which vary from focal cystic or solid lesions to diffuse parenchymal process considerable overlap in the sonographic appearance of different pathologic processes often necessities needle aspiration for achieving a definitive diagnosis. $^{7}$

Hepatic space occupying lesions are one of the most serious illnesses in human being. Hepatic SOL may be benign, malignant and have different histological subtypes. It is important to select an appropriate method for diagnosis. With the advent of Ultra sonogram and comparison with USG guided FNAC there is revolutionary change in the diagnosis of hepatic SOL. Ultra-sonogram and comparison with USG guided FNAC are now one of the techniques of choice for investigating most suspected lesions of liver. It is an easy, cheap and available method for diagnosis SOL in liver. This imaging modality is also relatively accurate and less time consuming. So we can radiologically help early evaluation and management of hepatic SOL. For this reason, this study has been undertaken to assess the usefulness of ultrasonography and comparison of USG guided FNAC for evaluation of different types of solid space occupying lesion in liver.

\section{Materials and Methods}

This cross sectional study was carried out enrolling 47 subjects with clinically or radiologically diagnosed case of suspected case of solid SOL in the liver admitted in the hospital and sent for USG guided FNAC in the Department of Radiology and Imaging, Dhaka Medical College Hospital, from July 2012 to June 2013. All the patients with liver masses confirmed by ultrasonography, irrespective of age and gender, were included. Patients with inflammatory lesions were excluded from the study. Selected patients underwent fine-needle aspiration under ultrasound guidance followed by needle biopsy. The cytological slides were stained by hematoxylin and eosin ( $\mathrm{H} \& \mathrm{E})$ stain, while Papanicolaou's stain was employed in selective cases. Needle biopsy fragments were fixed in formalin followed by paraffin embedding and staining with $\mathrm{H}$ and $\mathrm{E}$ stain. . The study subjects were enrolled in this study after fulfillment of the inclusion criteria.

The objective of the study was discussed in details with the patients or their attendants before their decision to enroll themselves into the study. Clinical examination and laboratory tests were done and data collected. Demographic information was prospectively recorded and substantiated by means of inspection of medical record. Information included was the subject's age, gender, medical and clinical history, followed by conduction of the study. The present study was conducted in the Department of Radiology and 
Imaging in collaboration with Department of Pathology, Dhaka Medical College. After thorough clinical examination, ultra-sonographic examination was performed with Hitachi EUB$7000 \mathrm{HV}$ ultrasound machine having $3.5 \mathrm{MHz}$ sector (Mechanical) probe; and those found to have a mass were subjected to fine needle aspiration cytology by a $20-22 \mathrm{G}$ spinal needle. Smears prepared were fixed in $95 \%$ ethyl alcohol and stained with $\mathrm{H} \&$ E stain and Papanicolaou's stains.

First data was collected. The data were checked. Data analysis by SPSS version 20. Data were presented by means of table and charts. Diagnostic accuracy was measured by sensitivity, specificity, positive predictive value, negative predictive value and accuracy.

\section{Result}

To evaluate the diagnostic usefulness of USG in the diagnosis of solid SOL in the liver this cross sectional study was done on 47 purposively selected patients whose age ranged from 04 to 64 years.

In our study majority of the metastases were multiple (85\%), hypoechoic (35\%) and only $15 \%$ had internal calcifications. HCC was single lesion $(61.53 \%)$ with hyperechoic $(38.35 \%)$ echogenicity, with a central halo $(76.92 \%)$ and $15.38 \%$ had internal calcifications. Majority of the cholangiocarcinoma were solitary (80\%), hypoechoic $(60 \%)$ and $60 \%$ had internal calcifications. Hepatoblastoma were solitary and had calcifications $(60 \%)$ with mixed echogenicity $(60 \%)$. Majority of the adenomas were hypoechoic $(60 \%)$ and only $20 \%$ had internal calcifications.

Out of 47 cases, 20 cases $(42.55 \%)$ were diagnosed as metastasis and $13(27.67 \%)$ cases as HCC in USG. Cholangiocarcinoma and hepatoblastoma were found as $5(10.63 \%)$ cases each. Hepatic adenoma was $4(8.52 \%)$ in number. Among them 19 cases (40.44\%) were diagnosed as metastasis and $13(27.67 \%)$ cases as HCC in sono-guided FNAC. Cholangiocarcinoma, hepatoblastoma and hepatic Adenoma were found in five $(10.63 \%)$ cases. (Table I)
Table I: Comparison between USG finding and FNAC finding

\begin{tabular}{ccc}
\hline & $\begin{array}{c}\text { USG } \\
\text { finding }\end{array}$ & FNAC finding \\
\hline Metastasis & 20 & 19 \\
HCC & 13 & 13 \\
Cholangiocarcinoma & 5 & 5 \\
Hepatoblastoma & 5 & 5 \\
Hepatic Adenoma & 4 & 5 \\
\hline
\end{tabular}

Transabdominal sonographic diagnoses were correlated with the cytopathology diagnoses following collection of the reports from the respective cases. Of the total 47 cases diagnosis of 20 cases were metastasis. Cytopathology of the biopsied tissues confirmed 19 cases as metastasis and one case as adenoma.

The validity of transabdominal sonography for the diagnosis of metastasis was confirmed by calculating sensitivity (100\%), specificity (96.42\%), accuracy $(97.87 \%)$, positive $(95 \%)$ and negative predictive $(100 \%)$ values by using the standard formula given (Table II).

Table II: Comparison between transabdominal sonography of hepatic metastasis with cytopathology diagnoses

\begin{tabular}{|c|c|c|c|}
\hline \multicolumn{4}{|c|}{ Cytopathological diagnosis } \\
\hline $\begin{array}{l}\text { Sonographi } \\
\text { c diagnosis }\end{array}$ & $\begin{array}{l}\text { +ve for } \\
\text { metastas } \\
\text { is } \\
\text { (Disease } \\
\text { positive) }\end{array}$ & $\begin{array}{l}\text {-ve for } \\
\text { metastasis } \\
\text { (Disease } \\
\text { negative) }\end{array}$ & Total \\
\hline $\begin{array}{l}\text { +ve for } \\
\text { metastasis } \\
(\text { Test } \\
\text { positive })\end{array}$ & $\begin{array}{c}19 \\
\text { (True } \\
\text { positive } \\
=\mathrm{TP})\end{array}$ & $\begin{array}{c}01 \\
\text { (False } \\
\text { positive= } \\
\text { FP) }\end{array}$ & $\begin{array}{c}20 \\
(\mathrm{TP}+\mathrm{FP})\end{array}$ \\
\hline $\begin{array}{l}\text {-ve for } \\
\text { metastasis } \\
(\text { Test } \\
\text { negative })\end{array}$ & $\begin{array}{c}00 \\
\text { (False } \\
\text { negative } \\
=\mathrm{FN})\end{array}$ & $\begin{array}{c}27 \\
\text { (True } \\
\text { negative= } \\
\text { TN) }\end{array}$ & $\begin{array}{c}27 \\
(\mathrm{TN}+\mathrm{FN})\end{array}$ \\
\hline Total & $\begin{array}{c}19 \\
(\mathrm{TP}+\mathrm{FN})\end{array}$ & $\begin{array}{c}28 \\
(\mathrm{FP}+\mathrm{TN})\end{array}$ & $\begin{array}{c}47 \\
(\mathrm{TP}+\mathrm{FP}+\mathrm{TN}+ \\
\mathrm{FN})\end{array}$ \\
\hline
\end{tabular}

Of the total 47 cases diagnosis of 13 cases was HCC. Cytopathology of the biopsied tissues confirmed 12 cases as HCC and one case as hepatoblastoma. One hepatoblastoma was diagnosed as HCC. 
The validity of transabdominal sonography for the diagnosis of HCC was confirmed by calculating sensitivity, specificity, accuracy, positive and negative predictive values by using the standard formula given. The sensitivity, specificity, accuracy, positive and negative predictive values were $92.3 \%, 97.05 \%, 95.74 \%, 92.3 \%$ and $97.05 \%$ respectively (Table III).

Table III: Comparison between transabdominal sonography of HCC with cytopathology diagnoses

\begin{tabular}{|c|c|c|c|}
\hline \multicolumn{4}{|c|}{ Cytopathology diagnosis } \\
\hline $\begin{array}{c}\text { Sonographic } \\
\text { diagnosis }\end{array}$ & $\begin{array}{l}\text { +ve for } \\
\text { HCC } \\
\text { (Disease } \\
\text { positive) }\end{array}$ & $\begin{array}{c}\text {-ve for } \\
\text { HCC } \\
\text { (Disease } \\
\text { negative) }\end{array}$ & Total \\
\hline $\begin{array}{c}\text { +ve for HCC } \\
\text { (Test } \\
\text { positive) }\end{array}$ & $\begin{array}{c}12 \\
\text { (True } \\
\text { positive= } \\
\text { TP) }\end{array}$ & $\begin{array}{c}01 \\
\text { (False } \\
\text { positive= } \\
\text { FP) }\end{array}$ & $\begin{array}{c}13 \\
(\mathrm{TP}+\mathrm{FP})\end{array}$ \\
\hline $\begin{array}{c}\text {-ve for HCC } \\
\text { (Test } \\
\text { negative) }\end{array}$ & $\begin{array}{c}01 \\
(\text { False } \\
\text { negative } \\
=\mathrm{FN})\end{array}$ & $\begin{array}{c}33 \\
\text { (True } \\
\text { negative } \\
=\mathrm{TN} \text { ) }\end{array}$ & $\begin{array}{c}34 \\
(\mathrm{TN}+\mathrm{FN})\end{array}$ \\
\hline Total & $\begin{array}{c}13 \\
(\mathrm{TP}+\mathrm{FN})\end{array}$ & $\begin{array}{c}34 \\
(\mathrm{FP}+\mathrm{TN})\end{array}$ & $\begin{array}{c}47 \\
(\mathrm{TP}+\mathrm{FP}+\mathrm{TN} \\
+\mathrm{FN})\end{array}$ \\
\hline
\end{tabular}

Transabdominal sonographic diagnoses were comparison with the cytopathology diagnoses following collection of the reports from the respective cases. Of the total 47 cases diagnosis of 5 cases was cholangiocarcinoma. Cytopathology of the biopsied tissues confirmed four cases as cholangiocarcinoma and one case as adenoma. Again, one case was diagnosed as cholangiocarcinoma from metastasis group.

The validity of transabdominal sonography for the diagnosis of cholangiocarcinoma was confirmed by calculating sensitivity, specificity, accuracy, positive and negative predictive values by using the standard formula given. The sensitivity, specificity, accuracy, positive and negative predictive values were $80 \%, 97.61 \%, 95.74 \%$, $80 \%$ and $97.61 \%$ respectively (Table IV).

Of the total 47 cases diagnosis of five cases was hepatoblastoma. Cytopathology of the biopsied tissues confirmed four cases as hepatoblastoma and one case as HCC. One HCC was diagnosed as hepatoblastoma from HCC diagnosed cases.

The validity of transabdominal sonography for the diagnosis of hepatoblastoma was confirmed by calculating sensitivity, specificity, accuracy, positive and negative predictive values by using the standard formula given.

Table IV: Comparison between transabdominal sonography of cholangiocarcinoma with cytopathology diagnoses

\begin{tabular}{|c|c|c|c|}
\hline \multicolumn{4}{|c|}{ Cytopathology diagnosis } \\
\hline $\begin{array}{c}\text { Sonographic } \\
\text { diagnosis }\end{array}$ & $\begin{array}{l}\text { +ve for } \\
\text { cholangiocar } \\
\text { cinoma } \\
\text { (Disease } \\
\text { positive) }\end{array}$ & $\begin{array}{c}\text {-ve for } \\
\text { cholangiocar } \\
\text { cinoma } \\
\text { (Disease } \\
\text { negative) }\end{array}$ & Total \\
\hline $\begin{array}{c}\text { +ve for } \\
\text { cholangiocarci } \\
\text { noma } \\
\text { (Test positive) }\end{array}$ & $\begin{array}{c}04 \\
\text { (True } \\
\text { positive=TP) }\end{array}$ & $\begin{array}{c}01 \\
\text { (False } \\
\text { positive=FP) }\end{array}$ & $\begin{array}{c}05 \\
(\mathrm{TP}+\mathrm{FP})\end{array}$ \\
\hline $\begin{array}{c}\text {-ve for } \\
\text { cholangiocarci } \\
\text { noma } \\
\text { (Test negative) }\end{array}$ & $\begin{array}{c}01 \\
(\text { False } \\
\text { negative=FN) }\end{array}$ & $\begin{array}{c}41 \\
\text { (True } \\
\text { negative=TN) }\end{array}$ & $\begin{array}{c}42 \\
(\mathrm{TN}+\mathrm{FN})\end{array}$ \\
\hline Total & $\begin{array}{c}05 \\
(\mathrm{TP}+\mathrm{FN})\end{array}$ & $\begin{array}{c}42 \\
(\mathrm{FP}+\mathrm{TN})\end{array}$ & $\begin{array}{c}47 \\
(\mathrm{TP}+\mathrm{FP}+\mathrm{TN} \\
+\mathrm{FN})\end{array}$ \\
\hline
\end{tabular}

The sensitivity, specificity, accuracy, positive and negative predictive values were $80 \%, 97.61 \%$, $95.74 \%, 80 \%$ and $97.61 \%$ respectively (Table V).

Table V: Comparison between transabdominal sonography of hepatoblastoma with cytopathology diagnoses

\begin{tabular}{|c|c|c|c|}
\hline \multicolumn{4}{|c|}{ Cytopathology diagnosis } \\
\hline $\begin{array}{c}\text { Sonographic } \\
\text { diagnosis }\end{array}$ & $\begin{array}{c}\text { +ve for } \\
\text { Hepatobl } \\
\text { astoma } \\
\text { (Disease } \\
\text { positive) }\end{array}$ & $\begin{array}{c}\text {-ve for } \\
\text { Hepatoblas } \\
\text { toma } \\
\text { (Disease } \\
\text { negative) }\end{array}$ & Total \\
\hline $\begin{array}{c}\text { +ve for } \\
\text { Hepatoblast } \\
\text { oma } \\
\text { (Test } \\
\text { positive) }\end{array}$ & $\begin{array}{c}04 \\
\text { (True } \\
\text { positive=TP } \\
\text { ) }\end{array}$ & $\begin{array}{c}01 \\
\text { (False } \\
\text { positive=FP) }\end{array}$ & $\begin{array}{c}05 \\
(\mathrm{TP}+\mathrm{FP})\end{array}$ \\
\hline $\begin{array}{c}\text {-ve for } \\
\text { Hepatoblast } \\
\text { oma } \\
\text { (Test } \\
\text { negative) }\end{array}$ & $\begin{array}{c}01 \\
\text { (False } \\
\text { negative=F } \\
\mathrm{N})\end{array}$ & $\begin{array}{c}41 \\
(\text { True } \\
\text { negative=TN) }\end{array}$ & $\begin{array}{c}42 \\
(\mathrm{TN}+\mathrm{FN})\end{array}$ \\
\hline Total & $\begin{array}{c}05 \\
(\mathrm{TP}+\mathrm{FN})\end{array}$ & $\begin{array}{c}42 \\
(\mathrm{FP}+\mathrm{TN})\end{array}$ & $\begin{array}{c}47 \\
(\mathrm{TP}+\mathrm{FP}+\mathrm{TN} \\
+\mathrm{FN})\end{array}$ \\
\hline
\end{tabular}

Of the total 47 cases diagnosis of four cases was adenoma. Cytopathology of the biopsied tissues confirmed four cases as adenoma. One metastasis was diagnosed as adenoma.

The validity of transabdominal sonography for the diagnosis of adenoma was confirmed by calculating sensitivity, specificity, accuracy, 
positive and negative predictive values by using the standard formula given. The sensitivity, specificity, accuracy, positive and negative predictive values were $80 \%, 100 \%, 97.87 \%$, $100 \%$ and $97.67 \%$ respectively (Table VI).

Table VI: Comparison between transabdominal sonography of adenoma with cytopathology diagnoses

\begin{tabular}{|c|c|c|c|}
\hline \multicolumn{4}{|c|}{ Cytopathology diagnosis } \\
\hline $\begin{array}{c}\text { Sonograp } \\
\text { hic } \\
\text { diagnosis }\end{array}$ & $\begin{array}{l}\text { +ve for } \\
\text { adenoma } \\
\text { (Disease } \\
\text { positive) }\end{array}$ & $\begin{array}{l}\text {-ve for } \\
\text { adenoma } \\
\text { (Disease } \\
\text { negative) }\end{array}$ & Total \\
\hline $\begin{array}{l}\text { +ve for } \\
\text { adenoma } \\
\text { (Test } \\
\text { positive) }\end{array}$ & $\begin{array}{c}04 \\
\text { (True } \\
\text { positive=TP) }\end{array}$ & $\begin{array}{c}00 \\
\text { (False } \\
\text { positive=FP) }\end{array}$ & $\begin{array}{c}04 \\
(\mathrm{TP}+\mathrm{FP})\end{array}$ \\
\hline $\begin{array}{l}\text {-ve for } \\
\text { adenoma } \\
\text { (Test } \\
\text { negative) }\end{array}$ & $\begin{array}{c}01 \\
(\text { False } \\
\text { negative= } \\
\text { FN) }\end{array}$ & $\begin{array}{c}42 \\
\text { (True } \\
\text { negative= } \\
\text { TN) }\end{array}$ & $\begin{array}{c}43 \\
(\mathrm{TN}+\mathrm{FN})\end{array}$ \\
\hline Total & $\begin{array}{c}05 \\
(\mathrm{TP}+\mathrm{FN})\end{array}$ & $\begin{array}{c}42 \\
(\mathrm{FP}+\mathrm{TN})\end{array}$ & $\begin{array}{c}47 \\
(\mathrm{TP}+\mathrm{FP}+\mathrm{TN}+ \\
\mathrm{FN})\end{array}$ \\
\hline
\end{tabular}

\section{Discussion}

Sonographic visualization of a solid hepatic mass might occur in a variety of clinical sceneries ranging from incidental detection to identification in a symptomatic patient or as a part of focused search in a patient at least for hepatic neoplasm. ${ }^{1}$ On a sonographic study, there is considerable overlap in the appearance of solid liver mass but careful survey in different planes and angles, ultrasonography is helpful in detection and characterization of solid mass. Majority of solid liver mass appears as an echogenic or isoechoic liver mass with surrounding hypoechoic halo. A hypoechoic mass is highly likely to be significant and requires further definitive characterization. Multiple solid liver masses might arise the probability of metastatic or multifocal malignant liver disease. ${ }^{4}$ Ultrasound with USG guided needle biopsy is an important diagnostic technique in radiology practices throughout the world. It has become an accurate, safe and widely accepted technique for confirmation of different suspected hepatic mass and decrease patient costs by obviating the need for an operation, decreasing the duration of hospital stay and decreasing the number of examination necessary during a diagnostic evaluation. Traditionally, ultrasoundguided needle biopsy has been used for the biopsy of large, superficial masses but recently small, deeply located and solid masses can also undergo accurate biopsy.6 This present cross sectional study was carried out to find out the role of ultrasonography and USG guided fine needle aspiration cytology in the diagnosis of different types of liver mass. The findings of the study are discussed on basis of related previous studies concerning the objectives of the study.

This present study revealed that majority of the subjects was in 41-60 years' age group and male were more prevailed that female. In a comparable previous study, the mean age at presentation of solid liver lesion was 55 years with male to female ratio of 1.7:1 which was conducted Nazir et al. ${ }^{8}$

In our study, majority of the subjects with adenoma were female and most of the lesions were hypoechoic $(60 \%)$ to mixed echogenic and only $20 \%$ had internal calcifications. Sonographic appearances of hepatic adenoma were nonspecific. ${ }^{9}$ They might be either hypoechoic, isoechoic or mixed. When hemorrhage occurs, there is a fluid component situated in or around the mass. Sometimes intraperitoneal blood is seen as hypoechoic fluid. ${ }^{10}$ The sensitivity, specificity, accuracy, positive and negative predictive values for sonographic diagnosis of adenoma were $80 \%$, $100 \%, 97.87 \%, 100 \%$ and $97.67 \%$ respectively.

The most common solid liver tumor among elderly patients is metastatic liver disease. Common site of primary tumor is gallbladder, colon, stomach, pancreas, breast and lung. ${ }^{11}$ Most metastasis is blood born but may also be due to lymphatic spread. Advantages of ultrasound for metastatic solid lesion are relative accuracy, speed, lack of ionization and availability. On conventional sonography metastatic disease may either focal or multiple. ${ }^{12}$ In present study, majority of the metastases were multiple (85\%), hypoechoic $(35 \%)$ and only $15 \%$ had internal calcifications. Similar comparable findings were elucidating in another study. According to that study on sonography they had echogenic, hypoechoic, cystic, calcified and diffused altered echogenicity..$^{11}$ Often they are surrounded by a hypoechoic halo giving rise to target sign. Although studies ${ }^{13,14}$ reported presence of hypoechoic halo in benign as well as malignant hepatocellular carcinoma, the presence of hypoechoic halo in metastatic disease had positive and negative predictive value of $86 \%$ and $88 \%$ 
respectively. The validity of transabdominal sonography for the diagnosis of metastasis was confirmed by calculating sensitivity (100\%), specificity (96.42\%), accuracy (97.87\%), positive $(95 \%)$ and negative predictive $(100 \%)$ values in current study. Takanobu Yashida et al. ${ }^{15}$ found Sensitivity $78 \%$, specificity $99 \%$, positive (96.8\%) and negative predictive $(97.1 \%)$ in their study for ultra-sonographic diagnosis of hepatic metastases.

Hepatocellular carcinoma occurs as solitary tumor, multiple nodules or as diffused infiltration. Sonographic appearance of HCC may be hypoechoic, echogenic up to complex echo texture. Most of the small $(<5 \mathrm{~cm})$ lesions are hypoechoic. ${ }^{16}$ In the present study HCC was single lesion (61.53\%) with hyperechoic (38.35\%) echogenicity, hypoechoic echogenicity (30.77\%). A central halo (76.92\%) and internal calcifications $(15.38 \%)$ were also seen. There was peripheral halo in some lesion (15.38\%) also in present study. Researchers described that a thin peripheral halo which corresponds to fibrous capsule in seen in most of the hepatocellular carcinoma. ${ }^{17}$ With time and increasing size the mass tends to be more complex and in homogeneous as a result of hemorrhage and necrosis. So during FNAC, one should take material from periphery of the lesion to get maximum malignant cells. If material is collected from the center, necrotic material will be collected and give false result. Calcification is uncommon in HCC. Small tumors might appear diffusely hypoechoic. Multifocal solid hepatocellular carcinoma is sometimes difficult to differentiate to multifocal metastasis. Similar difficulty on sonographic diagnosis on solid liver mass had arouse in previous study also. ${ }^{18}$ History of existing chronic liver disease and absence known primary malignancy helps to differentiate hepatocellular carcinoma from metastasis. ${ }^{11}$ The sensitivity, specificity, accuracy, positive and negative predictive values were $92.3 \%, 97.05 \%$, $95.74 \%, 92.3 \%$ and $97.05 \%$ respectively for HCC in present study. Similar comparable findings were seen in other studies. ${ }^{19,20}$

Depending on the tumor type, the sensitivity of ultrasonography in depicting cholangiocarcinoma was variable. ${ }^{21}$ In our study majority of the cholangiocarcinoma were solitary $(80 \%)$, hypoechoic $(60 \%)$ and $60 \%$ had internal calcifications. Dilatation of the intrahepatic bile ducts was the most common abnormality in patients with ductal cholangiocarcinoma. With intrahepatic tumors, the mass could be a predominantly homogeneous or heterogeneous lesion, and it is usually hyperechoic in $75 \%$ of cases. The mass might be isoechoic (about $10 \%$ of cases) or hypoechoic ( $15 \%$ of cases) with irregular borders and satellite nodules. ${ }^{22}$ With the nodular type, the mass predominated and appeared as a solitary mass with a distinct predilection for the right lobe. Similar comparable study findings were revealed in previous study regarding cholangiocarcinoma. ${ }^{23}$ Similar result regarding cholangiocarcinoma was found in present study. The validity of transabdominal sonography for the diagnosis of cholangiocarcinoma was confirmed by calculating sensitivity, specificity, accuracy, positive and negative predictive values by using the standard formula given. The sensitivity, specificity, accuracy, positive and negative predictive values were $92.3 \%, 97.05 \%, 95.74 \%$, $92.3 \%$ and $97.05 \%$ respectively.

Among solid lesion in pediatric age group, Hepatoblastoma is the commonest. ${ }^{24}$ In this study we found, Hepatoblastoma were solitary $(100 \%)$ and had calcifications (60\%) with mixed echogenicity (60\%). According to other studies in Hepatoblastoma, the liver is hugely enlarged with hypo to mixed echogenic solid lesion. Occasionally the whole liver is replaced by diffuse lesion. ${ }^{25}$ Sometimes calcification is present within lesion. Careful survey shows displacement of adjacent vascular structures rather encasement. ${ }^{24}$ The sensitivity, specificity, accuracy, positive and negative predictive values were $80 \%, 100 \%$, $97.87 \%, 100 \%$ and $97.67 \%$ respectively in current study. Similar finding was seen in previous study among pediatric age group subjects with solid liver lesion. ${ }^{26}$

According to results of our study it can be said that Ultrasonography was able to diagnose almost accurately various focal liver lesion. However, for the accurate final diagnosis - FNAC examination is needed, as the tissue type cannot be detected by ultrasonography. On the other hand, ultrasonography aid in proper localization of focal liver lesion such that FNAC can be done from appropriate site without much false negative results. Ultrasonography and comparison with USG guided FNAC has become an indispensable component in the evaluation of focal liver lesions 
Conclusion: As the ultra-sonographic and USG guided FNAC finding of hepatic lesions correlates well with cytological findings, providing satisfactory FNA materials and the validity tests are almost identical as observed by other investigators, it can be concluded that the use of ultra-sonogram and USG guided FNAC can be accepted as a sensitive and reliable methods for diagnosis of various space occupying lesion in liver.

\section{References}

1. Mallikarjuna CMS, Kodandaswamy CR. Value of ultrasonography-guided fine needle aspiration cytology in the investigative sequence of hepatic lesions with an emphasis on hepatocellular carcinoma. J Cytol. 2011; 28(4):178-84.

2. Ji Xiao-Long. Fine-needle aspiration cytology of liver disease. WJG, 1999; 5(2):95-97.

3. Celik H, Ozdemir H, Yucel C, Gultekin S, Oktar SO, Arac M. Characterization of hyperechoic focal liver lesions. Journal of Ultrasound in Medicine, 2005; 24(1):39-47.

4. Chhieng DC. Fine needle aspiration biopsy of liveran update. World Journal of Surgical Oncology, 2004;2(5):1-8.

5. Asghar F, Riaz S. Diagnostic accuracy of percutaneous cytodiagnosis hepatic masses, by ultrasound guided fine needle aspiration cytology. Annals, 2010;16(3):184-87.

6. Thomas Atwell, J. William Charboneau, John McGahan, and Carl C. Reading. Ultrasound guided biopsy and drainage of the abdomen and pelvis, Rumach MC, Wilson RS, Charboneau JW (eds.). In: Diagnostic Ultrasound, 4th edition, Elsevier Mosby, 2005; 613-38.

7. White ME. USG examination of the solid abdominal viscera. Gore RM, Levine MS, Laufer I (eds.). In: Text book of gastro-intestinal Radiology. 1st edn, WB Saunders Company, 1994; 2:1506-17.

8. Nazir RT, Sharif MA, Iqbal M, Amin MS. Diagnostic accuracy of fine needle aspiration cytology in hepatic tumours. J Coll Physicians Surg Pak. 2010;20(6):373-76.

9. Micchelli ST, Vivekanandan P, Boitnott JK, Pawlik TM, Choti MA, Torbenson M. Malignant transformation of hepatic adenomas. Mod Pathol. 2008;21(4):491-97.

10. Herman P, Pugliese V, Machado MA, Montagnini AL, Salem MZ, Bacchella T, D'Albuquerque LA,
Saad WA, Machado MC, Pinotti HW. Hepatic adenoma and focal nodular hyperplasia: differential diagnosis and treatment. World J Surg. 2000;24(3):372-76.

11. Kinkel K, Lu Y, Both M. Detection of hepatic metastases from cancers of the gastrointestinal tract by using noninvasive imaging methods (US, CT, MR imaging, PET): a meta-analysis. Radiology. 2002;224(3):748-56.

12. Wittenberg J. MRI of hepatic metastatic disease. In: Ferrucci JT, Stark DD. Liver Imaging: Current Trends and New Techniques. 2nd edition, Boston, Mass: Andover Medical Publishers; 1990;153-61.

13. Adam A. Interventional radiology in the treatment of hepatic metastases. Cancer Treat Rev. 2002; 28(2):93-99.

14. Boykin KN, Zibari GB, Lilien DL. The use of FDGpositron emission tomography for the evaluation of colorectal metastases of the liver. Am Surg.1999;65(12):1183-85.

15. Yoshida T, Histomatsu, Nobuookazaki. Preoperative ultrasonography screening for liver metastasis of patients with colorectal carcinoma. Japanese Journal of Clinical Oncology, 2000;10(2):112-15.

16. Maturen KE, Wasnik AP, Bailey JE, Higgins EG, Rubin JM. Posterior acoustic enhancement in hepatocellular carcinoma. J Ultrasound Med. 2011;30(4):495-99.

17. Gheorghe L, Iacob S, Gheorghe C. Real-time sonoelastography - a new application in the field of liver disease. J Gastrointestin Liver Dis. 2008;17(4):469-74.

18. Ma Y, Zhang XL, Li XY, Zhang L, Su HH, Zhan CY. Value of computed tomography and magnetic resonance imaging in diagnosis and differential diagnosis of small hepatocellular carcinoma. Nan Fang Yi Ke da Xue Xue Bao. 2008;28(12):2235-38.

19. Cottone M, Marcenò MP, Maringhini A, Rinaldi F, Russo G, Sciarrino E, Turri M, Pagliaro L. Radiology;1983;147:517-19.

20. Buscarini L, Sbolli G, Cavanna L, Civardi G, Rossi S, Distasi S. Clinical and diagnostic features of 67 cases of hepatocellular carcinoma. Oncology, 1987;44(2):93-97.

21. Guglielmi A, Ruzzenente A, Campagnaro T, Pachera S, Valdegamberi A, Capelli P, et al. Does intrahepatic cholangiocarcinoma have better prognosis compared to perihilar cholangiocarcinoma? J Surg Oncol. 2010; 101(2):111-15. 
22. Gakhal MS, Gheyi VK, Brock RE, Andrews GS Multimodality imaging of biliary malignancies. Surg Oncol Clin N Am. 2009; 18(2):225-39.

23. Ariff B, Lloyd CR, Khan S, Shariff M, Thillainayagam AV, Bansi DS, et al. Imaging of liver cancer. World J Gastroenterol. 2009; 15(11):1289300.

24. Douglass EC. Hepatic malignancies in childhood and adolescence (hepatoblastoma, hepatocellular carcinoma, and embryonal sarcoma). Cancer Treat Res. 1997; 92:201-12.

25. Herzog CE, Andrassy RJ, Eftekhari F. Childhood cancers: hepatoblastoma. Oncologist. 2000; 5(6):445-53.

26. Litten JB, Tomlinson GE. Liver tumors in children. Oncologist. 2008;13(7):812-20. 